OPEN ACCESS

Edited by:

Mingjun Wang,

Xi'an Jiaotong University, China

Reviewed by:

Wenzhong Zhou,

Sun Yat-sen University, China

Muhammad Saeed,

East China University of Technology,

China

Rulei Sun,

Harbin Engineering University, China

${ }^{*}$ Correspondence:

Ho Jin Ryu

hojinryu@kaist.ac.kr

Specialty section:

This article was submitted to

Nuclear Energy,

a section of the journal

Frontiers in Energy Research

Received: 09 January 2021

Accepted: 02 March 2021

Published: 19 March 2021

Citation:

Mistarihi Q and Ryu HJ (2021) Finite-Element Simulation of Residual

Stresses During the Processing

of Lumped Burnable Absorber Fuel.

Front. Energy Res. 9:651339.

doi: 10.3389/fenrg.2021.651339

\section{Finite-Element Simulation of Residual Stresses During the Processing of Lumped Burnable Absorber Fuel}

\author{
Qusai Mistarihi and Ho Jin Ryu* \\ Department of Nuclear and Quantum Engineering, KAIST, Daejeon, South Korea
}

$\mathrm{UO}_{2}-\mathrm{Gd}_{2} \mathrm{O}_{3}$ fuel is mostly used as a burnable absorber fuel in the form of a homogenous mixture of $\mathrm{Gd}_{2} \mathrm{O}_{3}$ and $\cup_{2}$. More effective reactivity control can be achieved by lumping $\mathrm{Gd}_{2} \mathrm{O}_{3}$ within the $\mathrm{UO}_{2}$ because this enhances the spatial selfshielding factor of the burnable absorber fuel. The fabrication of lumped burnable absorber fuel containing lumped $\mathrm{Gd}_{2} \mathrm{O}_{3}$ spherical particles or compacts has been experimentally demonstrated using yttrium-stabilized zirconia (YSZ) as a $\mathrm{UO}_{2}$ fuel surrogate. Interfacial cracks or gaps forming under the interfacial stress that develops during the fabrication of the fuel can be eliminated by controlling the initial density of the lumped $\mathrm{Gd}_{2} \mathrm{O}_{3}$. In this study, this interfacial stress during the fabrication process was simulated using finite element methods. The effect of the size, shape, and initial density of the lumped $\mathrm{Gd}_{2} \mathrm{O}_{3}$ on the distribution and magnitude of the interfacial stress was investigated. The addition of $\mathrm{Gd}_{2} \mathrm{O}_{3}$ spherical particles resulted in a lower and more uniform interfacial stress distribution than the addition of cylindrical $\mathrm{Gd}_{2} \mathrm{O}_{3}$ compacts. The interfacial stress was increased with increasing $\mathrm{Gd}_{2} \mathrm{O}_{3}$ size and initial density. The calculated interfacial stress was compared with experimental results to estimate the threshold stress for crack development in a lumped burnable absorber fuel.

Keywords: finite element analysis, sintering stress, lumped burnable absorber fuel, interfacial cracks, shrinkage mismatch

\section{INTRODUCTION}

The potential use of Gd as a burnable absorber was recognized many years ago, considering its extremely high thermal neutron absorption cross-section. Gd is usually used in the form of $\mathrm{Gd}_{2} \mathrm{O}_{3}$ uniformly mixed with $\mathrm{UO}_{2}$ as a fuel matrix. Owing to the relatively high thermal neutron absorption cross-section, few fuel rods must contain $\mathrm{Gd}_{2} \mathrm{O}_{3}$. However, the main limitations of $\mathrm{Gd}_{2} \mathrm{O}_{3}$ are the significant end-of-cycle penalty due to the existence of Gd isotopes with higher thermal neutron absorption cross-sections (i.e., ${ }^{155} \mathrm{Gd}$ and ${ }^{157} \mathrm{Gd}$ ) (Grossbeck et al., 2001) and the degradation of the fuel's thermophysical properties (IAEA, 1995; Durazzo et al., 2013; Choe et al., 2016a). One possible way to overcome these limitations is changing the design of the $\mathrm{UO}_{2}-\mathrm{Gd}_{2} \mathrm{O}_{3}$ mixed fuel.

Several burnable absorber fuel designs have been developed for small modular pressurized water reactors (SMPWRs) in order to eliminate the use of soluble boron and improve the reactor performance in terms of increasing the fuel cycle length while maintainig a flat power distribution. 
Choe et al. (2016b) have proposed the use of a thin-layer of $\mathrm{Zr}$ ${ }^{167} \mathrm{Er}(\sim 0.1-0.2 \mathrm{~mm})$ on the inner side of the cladding as a new burnable absorber fuel design. A low burn-up swing of $548 \mathrm{pcm}$ and cycle length of 26.5 months can be obtained for SMPWRs loaded with this burnable absorber fuel design. Another advanced burnable absorber fuel design integrated four azimuthally $\mathrm{B}_{4} \mathrm{C}$ pads, with a thickness up to $90 \mu \mathrm{m}$ and span up to $70^{\circ}$, in the guide-thimble ring (Yahya and Kim, 2017a). This burnable absorber fuel design achieved a cycle length of about 53 months and a burnup swing between 634 and $800 \mathrm{pcm}$. Recently, a new design for burnable absorber fuel, called centrally shielded burnable absorber (CSBA), was developed (Nguyen et al., 2019). The CSBA comprises lumped $\mathrm{Gd}_{2} \mathrm{O}_{3}$ in the center of a $\mathrm{UO}_{2}$ fuel pellet. The lumping of $\mathrm{Gd}_{2} \mathrm{O}_{3}$ results in a slower burn-out rate and longer suppression of the excess of reactivity due to spatial self-shielding effect (Galperin et al., 1986; Yahya and Kim, 2017b). It was found that the spherically lumped burnable absorber has a higher self-shielding factor than other lumped burnable absorber designs like cylindrical or slab due to the its higher volume-tosurface-area ratio (Fleming, 1982). Nguyen et al. (2019) studied the effect of the size and number of spherically lumped $\mathrm{Gd}_{2} \mathrm{O}_{3}$, and found that a more excess reactivity subression and flat power distribution can be obtained by increasing the $\mathrm{Gd}_{2} \mathrm{O}_{3}$ sphere radius from $1 \mathrm{~mm}$ to $1.3 \mathrm{~mm}$ or the number of $\mathrm{Gd}_{2} \mathrm{O}_{3}$ sphere (radius $=1 \mathrm{~mm}$ ) from 1 to 3 . They found that a low burn-up swing ( $\sim 1100 \mathrm{pcm})$, long cycle length ( $\sim 37$ months), and higher burnup $(\sim 30 \mathrm{GWd} / \mathrm{tU})$ can be obtained for a small modular reactor loaded with one $\mathrm{Gd}_{2} \mathrm{O}_{3}$ sphere (radius $=1.69 \mathrm{~mm}$ ) in the center, two $\mathrm{Gd}_{2} \mathrm{O}_{3}$ spheres (radius $=1.26 \mathrm{~mm}$ ) in the intermediate region, three $\mathrm{Gd}_{2} \mathrm{O}_{3}$ spheres (radius $=0.7 \mathrm{~mm}$ ) in the outer region (Nguyen et al., 2019). The fabrication of CSBA using yttria-stabilized zirconia (YSZ) as a surrogate for $\mathrm{UO}_{2}$ and either lumped $\mathrm{Gd}_{2} \mathrm{O}_{3}$ pellets, spherical particles, or rods was recently demonstrated (Mistarihi et al., 2018).

One of the major challenges in CSBA fuel design is the formation of interfacial cracks that may form under the stress mismatch developed during the sintering or cooling processes. This may arise from mismatches in the densification and thermal expansion coefficients (TECs), as well as phase transformations, of the sintered materials (Sglavo and Bellettati, 2017). The existence of these interfacial cracks can increase the intensity of fuel cracking during reactor operation and eventually limit fuel performance. In our previous study (Mistarihi et al., 2018), we concluded that interfacial cracks were not formed in YSZ pellets containing lumped $\mathrm{Gd}_{2} \mathrm{O}_{3}$ because of the TEC mismatch or the phase transformation of $\mathrm{Gd}_{2} \mathrm{O}_{3}$. The TECs of YSZ and $\mathrm{Gd}_{2} \mathrm{O}_{3}$ are similar and interfacial cracks were absent from $\mathrm{Gd}_{2} \mathrm{O}_{3}$ mini-pellets pre-sintered at temperatures below the phase transformation temperature. Thus, interfacial cracks could be mainly attributed to the sintering stresses resulting from the shrinkage rate mismatch.

Several factors control the sintering stresses that develop during the processing of composites, including shrinkage rate mismatch, volume fraction, and the shape and size of inclusions (Davidge and Green, 1968). The results of our previous study (Mistarihi et al., 2018) showed that, in YSZ oxide pellets containing lumped $\mathrm{Gd}_{2} \mathrm{O}_{3}$ mini-pellets, interfacial cracks were formed only when using mini-pellets with high initial densities. However, no interfacial cracks were observed in the case of YSZ oxide pellets containing lumped $\mathrm{Gd}_{2} \mathrm{O}_{3}$ spherical particles with high initial densities. The fabricated $\mathrm{Gd}_{2} \mathrm{O}_{3}$ spherical particles and mini-pellets had similar relative densities, but they differed in size and shape. Therefore, the effect of the shape, size, and shrinkage rate of the lumped $\mathrm{Gd}_{2} \mathrm{O}_{3}$ on the formation of interfacial cracks during the manufacturing of $\mathrm{YSZ}$ oxide pellets containing lumped $\mathrm{Gd}_{2} \mathrm{O}_{3}$ is investigated in this study.

One method to investigate interfacial crack formation during the processing of composites is to determine the stress distribution. By determining the stress distribution, areas of high stress concentration can be located. These areas are important for the integrity of composites because failure, signified by the formation of interfacial cracks, begins in them (Agarwal, 1972). Several analytical studies based on the theory of elasticity have been performed to determine stress distributions in composites using simplified physical models such as spherical particles (Selsing, 1961) or fibers (Delale, 1988) distributed in infinite matrices. However, the behaviors of powder compacts during sintering are not elastic, and the relationship between the stress and deformation during the sintering process is complex. Nonetheless, the finite-element analysis (FEA) method allows the implementation of complex stress-deformation relationships and the analysis of complex geometries.

Because powder compacts exhibit viscoelastic behaviors, several phenomenological models have been developed to describe their behaviors during sintering. Riedel et al. (1993), using a simple $2 \mathrm{D}$ hexagonal grain structure with pores at the triple points, developed an isotropic linear viscous constitutive equation to describe sintering-dominated grain boundary diffusion. Olevsky (1998) developed a phenomenological model based on the continuum theory of sintering by determining the sintering parameters from the rheological behaviors of porous materials during sintering. This model was implemented in an FEA code (COMSOL) and used to study the sintering behavior of different powder compacts $\left(\mathrm{Al}_{2} \mathrm{O}_{3}\right.$ and $\left.\mathrm{YSZ}\right)$ processed by spark plasma sintering (Olevsky et al., 2012) and microwave sintering (Manière et al., 2017). In these studies (Olevsky et al., 2012; Manière et al., 2017), FEA was mostly used to predict the shrinkage rate and temperature distribution of the powders during sintering. Li et al. (2020) used the finite element software (ABAQUS) to study the stress distribution in the cladding of dispersed plate-type fuel as a function of irradiation time and temperatures by implementing nuclear fuel correlation as a subroutine.

In this study, the Olevsky model for sintering was implemented in the COMSOL Multiphysics code and used to understand the stress distribution formed during the manufacturing of YSZ oxide pellets containing lumped $\mathrm{Gd}_{2} \mathrm{O}_{3}$. In addition, the applicability of the CSBA to $\mathrm{UO}_{2}$ was investigated, and the stress distribution in $\mathrm{UO}_{2}$ containing lumped $\mathrm{Gd}_{2} \mathrm{O}_{3}$ was determined and compared with that of the YSZ-based pellets. The novelty of this study is to estimate the stress distribution and magnitude in the lumped burnable absorber fuel design during the fabrication process. 


\section{MATERIALS AND METHODS}

\section{Governing Equations}

Thermal, mechanical (linear elastic and sintering), and densification models were coupled by the FEA method (COMOSOL Multiphysics 5.4 code) and used to study the temperature, stress, and density distributions during the manufacturing of $\mathrm{YSZ}$ or $\mathrm{UO}_{2}$ oxide pellets containing either lumped $\mathrm{Gd}_{2} \mathrm{O}_{3}$ spheres or mini-pellets. The heat-transfer model applied to the entire pellet is expressed by the following equation:

$$
\rho C_{\mathrm{p}} \frac{\partial \mathrm{T}}{\partial \mathrm{t}}+\nabla \cdot(-k \nabla \mathrm{T})=0
$$

where $\rho$ is the material density $\left(\mathrm{g} . \mathrm{cm}^{-3}\right), \mathrm{C}_{\mathrm{p}}$ is the heat capacity (J.kg $\left.{ }^{-1} \mathrm{~K}^{-1}\right)$, $\mathrm{T}$ is the temperature $(\mathrm{K}), \mathrm{t}$ is the time (s), and $\mathrm{k}$ is the thermal conductivity of the material $\left(\mathrm{W} \cdot \mathrm{m}^{-1} \cdot \mathrm{K}^{-1}\right)$.

The $\mathrm{Gd}_{2} \mathrm{O}_{3}$ spherical particle or mini-pellet was assumed to exhibit pure elastic behavior, wherein the relationship between the stress and deformation is expressed by Hooke's law:

$$
\sigma_{\mathrm{ij}}=\mathrm{C} \dot{\varepsilon}_{\mathrm{ij}}
$$

where $\sigma_{\mathrm{ij}}$ is the stress tensor $\left(\mathrm{N} . \mathrm{m}^{-2}\right), \dot{\varepsilon}_{\mathrm{ij}}$ is the strain tensor $\left(\mathrm{s}^{-1}\right)$, and $\mathbf{C}$ is a fourth-order tensor that is a function of the shear modulus $(G)$ and Young's modulus $(E)$ of the material.

The YSZ and $\mathrm{UO}_{2}$ powder compact was assumed to exhibit a non-linear viscous behavior expressed by Olevsky (1998) phenomenological model (Eqs 3-6) based on the continuum theory of sintering:

$$
\begin{gathered}
\sigma_{\mathrm{ij}}=\frac{1}{\mathrm{~A}(\mathrm{~T})}\left(\varphi \dot{\varepsilon}_{\mathrm{ij}}+\left(\psi-\frac{1}{3} \varphi\right) \dot{\mathrm{e}} \delta_{\mathrm{ij}}\right)+\mathrm{S} \delta_{\mathrm{ij}} \\
\mathrm{A}(\mathrm{T})=\frac{\mathrm{A}}{\mathrm{T}} \mathrm{e}^{-\frac{\mathrm{Q}}{\mathrm{RT}}} \\
\dot{\mathrm{e}}=\dot{\varepsilon}_{\mathrm{x}}+\dot{\varepsilon}_{\mathrm{y}}+\dot{\varepsilon}_{\mathrm{Z}} \\
\varphi=(1-\mathrm{P})^{2}, \psi=\frac{2}{3} \frac{(1-\mathrm{P})^{3}}{\mathrm{P}}, \mathrm{S}=\frac{3 \alpha}{\mathrm{r}}(1-\mathrm{P})^{2}
\end{gathered}
$$

where $A(T)$ is the creep rate factor having the form of an Arrhenius-type equation, $Q$ is the activation energy for deformation, $\mathrm{A}$ is a pre-exponential factor, $\varphi$ is the shear viscosity (Pa.s), $\Psi$ is the bulk viscosity (Pa.s), $\dot{e}$ is the shrinkage rate $\left(\mathrm{s}^{-1}\right)$, $\delta_{i j}$ is the identity tensor, $\mathrm{S}$ is the effective sintering stress $(\mathrm{Pa}), \mathrm{P}$ is the porosity, $\alpha$ is the surface energy $\left(\mathrm{J} \cdot \mathrm{m}^{-2}\right), \mathrm{Q}$ is the activation energy $\left(\mathrm{J} \cdot \mathrm{mol}^{-1}\right), \mathrm{R}$ is the gas constant $8.314\left(\mathrm{~J} \cdot \mathrm{mol}^{-1} \cdot \mathrm{K}^{-1}\right)$, and $r$ is the average particle radius $(\mathrm{m})$.

The densification of $\mathrm{YSZ}$ and $\mathrm{UO}_{2}$ during the manufacturing process is expressed as the evolution of density during the fabrication process. The density can be related to porosity using the following expression:

$$
\rho_{\mathrm{eff}}=\rho_{\mathrm{t}}(1-\mathrm{P})
$$

where $\rho_{\text {eff }}$ is the effective density of the material during the sintering process and $\rho_{t}$ is the theoretical density of the material. Therefore, the densification of $\mathrm{YSZ}$ and $\mathrm{UO}_{2}$ during the fabrication process can be calculated by the evolution of the porosity, which evolves according to the equation of mass conservation:

$$
\dot{\mathrm{P}}+\dot{\mathrm{e}} \mathrm{P}=\dot{\mathrm{e}}
$$

\section{Materials Properties}

For $\mathrm{Gd}_{2} \mathrm{O}_{3}$, the experimentally measured densities of the $1400^{\circ} \mathrm{C}, 1500^{\circ} \mathrm{C}$, and $1600^{\circ} \mathrm{C}$ pre-sintered $\mathrm{Gd}_{2} \mathrm{O}_{3}$ were obtained from our previous study (Mistarihi et al., 2018) and used in the simulation. These densities were approximately $6.29 \pm 0.13$, $7.10 \pm 0.04$, and $7.75 \pm 0.0 .6 \mathrm{~g} / \mathrm{cm}^{3}$, corresponding to relative densities (RDs) of $75.5 \pm 1.5,85.2 \pm 0.5$, and $93.4 \pm 0.8 \%$, respectively. The $\mathrm{RD}$ equals to the experimentally measured density divided by the theoretical density.

The elastic and shear moduli of $\mathrm{Gd}_{2} \mathrm{O}_{3}$ as functions of temperature for samples with an $\mathrm{RD}$ of $96.75 \%$ were measured by Dole and Hunter (1976). Haglund and Hunter (1973) measured the elastic properties of polycrystalline $\mathrm{Gd}_{2} \mathrm{O}_{3}$ with different initial porosities ranging from $2.5 \%$ to $36.7 \%$ as functions of temperature. The elastic properties were found to decrease linearly with the initial porosity of the sintered samples. The initial porosity of the sintered samples was varied by changing the sintering temperature (Haglund and Hunter, 1973). The reported values of $E$ and $G$ of $\mathrm{Gd}_{2} \mathrm{O}_{3}$ as functions of $T$ and $\mathrm{RD}$ were fitted to first-degree polynomials; the determined parameters of the fitting function are shown in Eqs 9 and 10.

$$
\begin{aligned}
\mathrm{E} & =0.00428 \times \mathrm{T}+265.30732 \times \mathrm{RD}-0.02349 \\
& \times \mathrm{T} \times \mathrm{RD}-117.14246 \\
\mathrm{G}= & 0.00158 \times \mathrm{T}+104.39288 \times \mathrm{RD}+0.00584 \times \mathrm{T} \\
& \times \mathrm{RD}-46.46078
\end{aligned}
$$

Using the experimentally measured RDs of the $1400^{\circ} \mathrm{C}, 1500$ ${ }^{\circ} \mathrm{C}$, and $1600{ }^{\circ} \mathrm{C}$ pre-sintered $\mathrm{Gd}_{2} \mathrm{O}_{3}, E$ and $G$ as functions of $T$ were calculated using Eqs 9 and 10.

The thermal conductivity of the fully sintered $\mathrm{Gd}_{2} \mathrm{O}_{3}$ as a function of temperature was experimentally measured using the laser flash method, and the results are shown in Figure 1. The thermal conductivity of fully dense $\mathrm{Gd}_{2} \mathrm{O}_{3}$ at temperatures higher than $800{ }^{\circ} \mathrm{C}$ was extrapolated from the experimentally measured data.

The thermal conductivities of the $1400{ }^{\circ} \mathrm{C}, 1500{ }^{\circ} \mathrm{C}$, and $1600{ }^{\circ} \mathrm{C}$ pre-sintered $\mathrm{Gd}_{2} \mathrm{O}_{3}$ as functions of $T$ were calculated from the thermal conductivity of the fully densified $\mathrm{Gd}_{2} \mathrm{O}_{3}$ using a modified Maxwell-Eucken correlation (Eq. 11):

$$
\mathrm{K}_{\mathrm{p}}=1.0789 \mathrm{~K}_{100}\left(\frac{1-\mathrm{P}}{1+0.5 \mathrm{P}}\right)
$$

where $\mathrm{K}_{100}$ and $\mathrm{K}_{\mathrm{p}}$ are the thermal conductivities of fully dense and porous $\mathrm{Gd}_{2} \mathrm{O}_{3}$, respectively. 
For YSZ, the thermal conductivity and heat capacity as a function of $T$ and density were provided by Manière et al. (2017) and used in the simulation (Eqs 12-13). The surface energy was provided by Tsoga and Nikolopoulos (1996) as given by Eq. 14. The density was calculated from the determined porosity. The average particle radius of $700 \mathrm{~nm}$ (Sigma Aldrich) was used in the simulation. The creep factor (Eq. 15) was determined by fitting the experimentally determined density of YSZ with those predicted by the FEA of YSZ oxide pellets without $\mathrm{Gd}_{2} \mathrm{O}_{3}$ spheres or mini-pellets. The density of YSZ was determined from the experimentally measured shrinkage of YSZ after correcting its TEC $\left(9.75 \times 10^{-6} \mathrm{~K}^{-1}\right)$ (Song et al., 2011).

$$
\begin{gathered}
\mathrm{k}=\left(1.96-2.32 \times 10^{-4} \mathrm{~T}+6.33 \times 10^{-7} \mathrm{~T}^{2}-1.91\right. \\
\left.\times 10^{-10} \mathrm{~T}^{3}\right)(1-1.5 \mathrm{P}) \\
\mathrm{C}_{\mathrm{p}}=\left\{\begin{array}{c}
\left(43+2.35 \mathrm{~T}-0.34 \times 10^{-3} \mathrm{~T}^{2}+4.25 \times 10^{-6} \mathrm{~T}^{3}-\right. \\
\left.2.09 \times 10^{-9} \mathrm{~T}^{4}+4.06 \times 10^{-13} \mathrm{~T}^{5}\right)(1-1.5 \mathrm{P}) \\
273<\mathrm{T}(\mathrm{K})<1473 \\
638(1-1.5 \mathrm{P}), 1473<\mathrm{T}(\mathrm{K})<2200
\end{array}\right. \\
\alpha=1.927-0.428 \times 10^{-3} \mathrm{~T} \\
A(T)=\left\{\begin{array}{c}
\frac{0.12}{T} e^{-\frac{200000}{R T}}, 273<T(K)<1300 \\
23 \times 10^{-10}\left(1-\frac{1}{1+e^{\frac{T-1895.58}{63}}}\right) \\
1300<T(K)<1800
\end{array}\right.
\end{gathered}
$$

For $\mathrm{UO}_{2}$, the surface energy as a function of $T$ from 273 to $3120 \mathrm{~K}$ was provided by Hall and Mortimer (1986). Fink (2000) summarized this reported data and provided a correlation for the mean value of the surface energy of $\mathrm{UO}_{2}$ as a function of $T$ (Eq. 16):

$$
\alpha=0.85-1.4 \times 10^{-4}(\mathrm{~T}-273.15)
$$

The heat capacity of the stoichiometric $\mathrm{UO}_{2}$ was measured by Kerrisk and Clifton (1972) over the temperature range 483-3107 $\mathrm{K}$. These data were summarized and fitted to Eq. 17 in MATPRO (Siefken et al., 2001):

$$
C_{p}=\frac{K_{1} M^{2} e^{\frac{\theta}{T}}}{T^{2}\left[e^{\frac{M}{T}}-1\right]^{2}}+K_{2} T+\frac{Y_{3} E_{D}}{2 R T^{2}} e^{\frac{-E_{D}}{R T}}
$$

where $Y$ is the oxygen-to-metal ratio (equal to 2 ), $\mathrm{R}$ is the universal gas constant $(8.3143 \mathrm{~J} / \mathrm{mol} \cdot \mathrm{K})$, and $\mathrm{M}$ is the Einstein constant (535.285). The constants $\mathrm{K}_{1}, \mathrm{~K}_{2}, \mathrm{~K}_{3}$, and $\mathrm{E}_{D}$ are equal to $296.7,2.43 \times 10^{-2}, 8.745 \times 10^{7}$, and $1.577 \times 10^{5}$.
Lucuta et al. (1996) summarized the thermal conductivity of non-irradiated and fully dense $\mathrm{UO}_{2}$ and fitted the data to a function comprising a hyperbolic term for the lattice contribution through phonon-defect and phonon-phonon scattering processes and an exponential term for polaron contributions. The exponential term becomes dominant for high temperatures $T>1900 \mathrm{~K}$.

$$
\mathrm{k}_{\mathrm{o}}=\frac{1}{0.0375+2.165 \times 10^{-4} \mathrm{~T}}+\frac{4.715 \times 10^{9}}{\mathrm{~T}^{2}} \mathrm{e}^{\frac{-16361}{\mathrm{~T}}}
$$

The creep factor of $\mathrm{UO}_{2}$ was generated in a similar way to that of YSZ and is expressed by Eq. 19.

$$
A(T)=\left\{\begin{array}{c}
\frac{0.12}{T} e^{-\frac{200000}{R T}}, 273<T(K)<1300 \\
30 \times 10^{-10}\left(1-\frac{1}{1+e^{\frac{T-1795.58}{100}}}\right) \\
1300<T(K)<1800
\end{array}\right.
$$

An average particle radius of $2400 \mathrm{~nm}$ was used for the simulation of $\mathrm{UO}_{2}$ (Yeo et al., 2013).

The shrinkage rates of the green $\mathrm{YSZ}, \mathrm{UO}_{2}$, and $\mathrm{Gd}_{2} \mathrm{O}_{3}$ compacts and the $1400{ }^{\circ} \mathrm{C}, 1500{ }^{\circ} \mathrm{C}$, and $1600{ }^{\circ} \mathrm{C}$ pre-sintered pellets were measured by a dilatometer (DIL 402C) up to $1600^{\circ} \mathrm{C}$ in an air atmosphere with a heating rate of $10^{\circ} \mathrm{C} / \mathrm{min}$ and a holding time of $3 \mathrm{~h}$. The results are shown in Figure 2.

\section{Geometric Models}

2-D axisymmetric simulation models were developed to study the sintering stress distributions during the fabrication process of YSZ pellets containing lumped $\mathrm{Gd}_{2} \mathrm{O}_{3}$ mini-pellets or spherical particles. The geometrical models used in the FEA simulations are shown in Figure 3.

In order to determine the critical sintering stress for cracking, simulation models of YSZ oxide pellets with a $\mathrm{Gd}_{2} \mathrm{O}_{3}$ mini-pellet pre-sintered at $1400^{\circ} \mathrm{C}, 1500^{\circ} \mathrm{C}$, or $1600^{\circ} \mathrm{C}$ having the average measured dimensions of the pre-sintered pellets (see Table 1) and the measured shrinkage rates of the pellets sintered at 1400, 1500, and $1600{ }^{\circ} \mathrm{C}$ (see Figure 2) were developed. Simulation models of YSZ oxide pellets containing either lumped $\mathrm{Gd}_{2} \mathrm{O}_{3}$ spherical particles or mini-pellets of the same size and the shrinkage rate of the $1400{ }^{\circ} \mathrm{C}$ pre-sintered pellets were also developed to understand the effect of the lumped $\mathrm{Gd}_{2} \mathrm{O}_{3}$ shape on the formation of interfacial cracks. In addition, simulation models of YSZ oxide pellets with lumped $\mathrm{Gd}_{2} \mathrm{O}_{3}$ spherical particles of $1.5,2$, or $3 \mathrm{~mm}$ in diameter and the shrinkage rate of the pellets pre-sintered at $1400{ }^{\circ} \mathrm{C}$ were developed to determine the critical size of the lumped $\mathrm{Gd}_{2} \mathrm{O}_{3}$ spherical particles. Finally, simulation models of YSZ oxide pellets with a $\mathrm{Gd}_{2} \mathrm{O}_{3}$ spherical particle having the shrinkage rate of the pellet at $1400{ }^{\circ} \mathrm{C}, 1500{ }^{\circ} \mathrm{C}$, or $1600^{\circ} \mathrm{C}$ and the size of $1.5 \mathrm{~mm}$ were developed to understand the effect of the shrinkage rate on the formation of interfacial cracks.

\section{Initial and Boundary Conditions}

The simulation models were assumed to have an initial temperature of $25{ }^{\circ} \mathrm{C}$. The outer surfaces of the simulation 


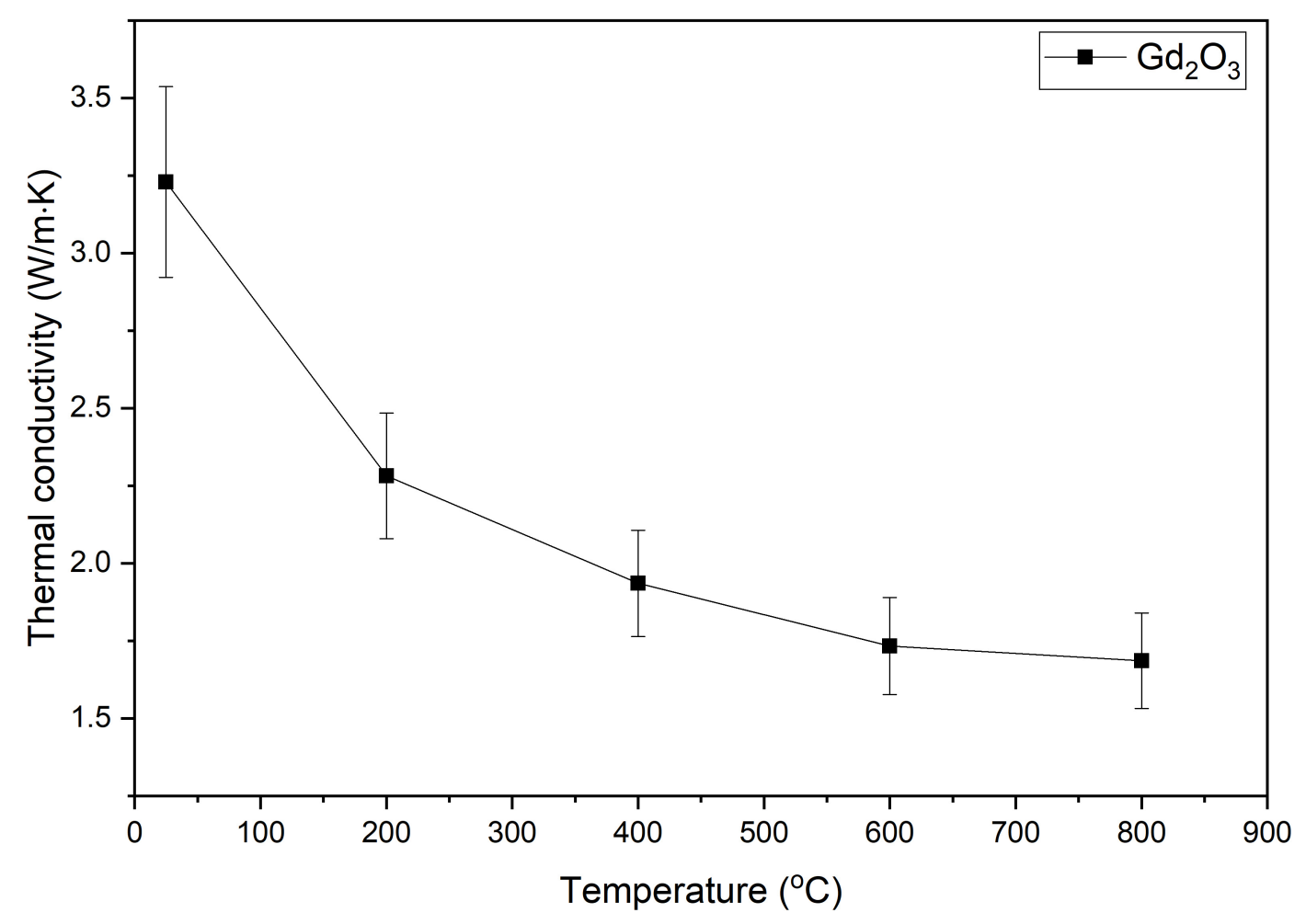

FIGURE 1 | Thermal conductivity of fully dense $\mathrm{Gd}_{2} \mathrm{O}_{3}$ with increases in sintering temperature from $25^{\circ} \mathrm{C}$ to $800{ }^{\circ} \mathrm{C}$.

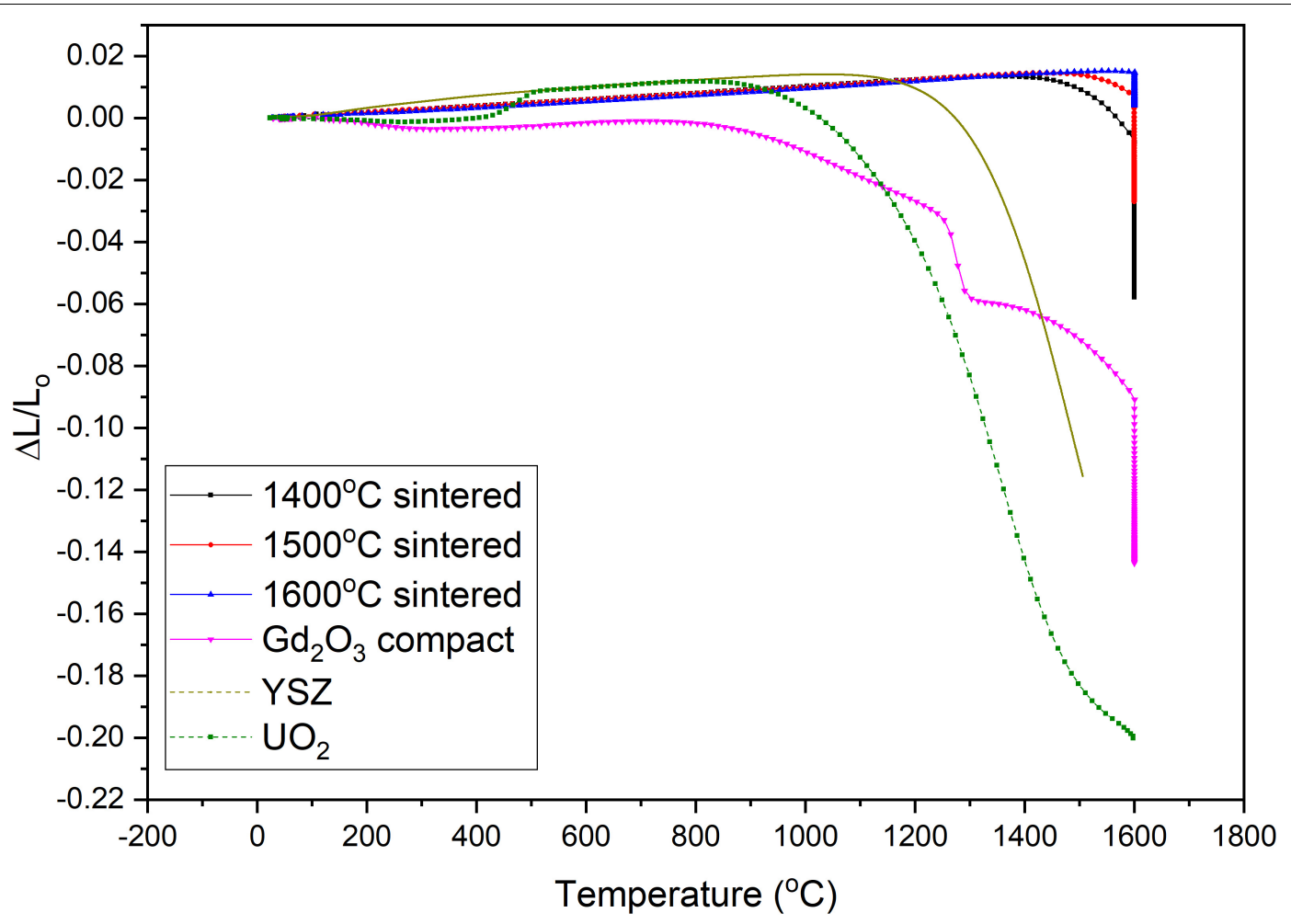

FIGURE 2 | Shrinkage behaviors of $\mathrm{Gd}_{2} \mathrm{O}_{3}$ compact, sintered $\mathrm{Gd}_{2} \mathrm{O}_{3}$ pellet, $\mathrm{YSZ}$ compact, and $\mathrm{UO}_{2}$ compact. 


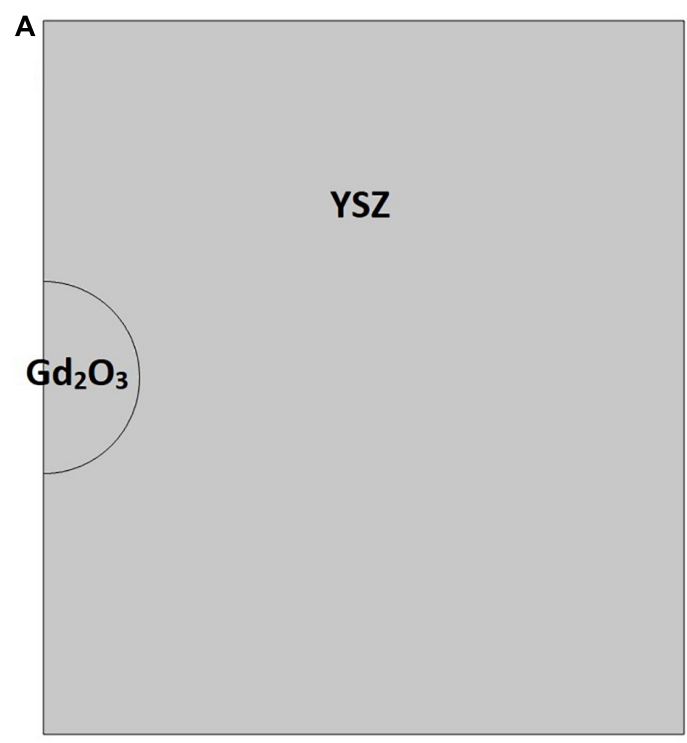

B

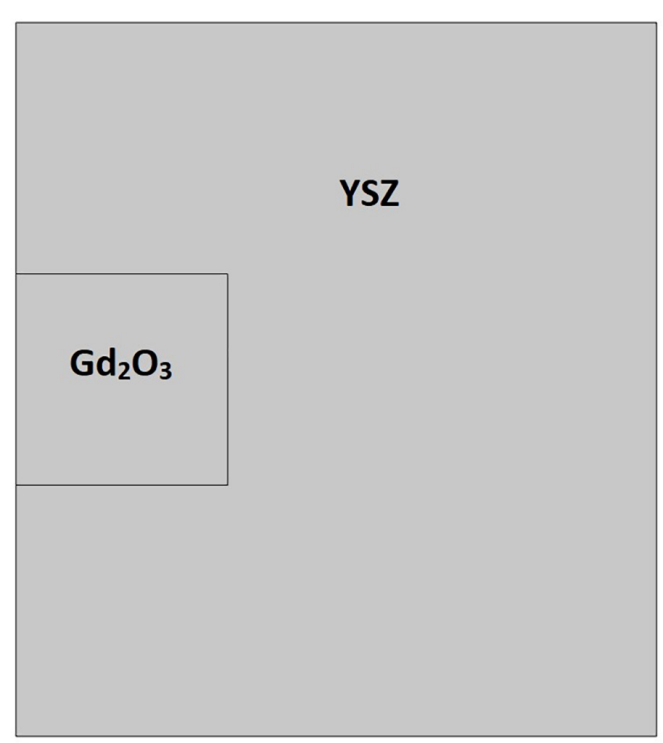

FIGURE 3 | Geometrical models of YSZ oxide pellet containing (A) lumped $\mathrm{Gd}_{2} \mathrm{O}_{3}$ spherical particle and (B) mini-pellet.

models of the YSZ oxide pellets containing a lumped $\mathrm{Gd}_{2} \mathrm{O}_{3}$ sphere or mini-pellet were heated from $25^{\circ} \mathrm{C}$ to $1500{ }^{\circ} \mathrm{C}$ or 1600 ${ }^{\circ} \mathrm{C}$ for the case of $\mathrm{YSZ}$ or $\mathrm{UO}_{2}$ with a heating rate of $10^{\circ} \mathrm{C} / \mathrm{min}$, in accordance with the experimental procedures.

\section{RESULTS AND DISCUSSION}

\section{YSZ pellet}

Figure 4 shows the FEA simulation results for the maximum sintering stress in YSZ oxide pellets containing a lumped $\mathrm{Gd}_{2} \mathrm{O}_{3}$ mini-pellet pre-sintered at $1400{ }^{\circ} \mathrm{C}, 1500{ }^{\circ} \mathrm{C}$, or $1600^{\circ} \mathrm{C}$ during heating from $25^{\circ} \mathrm{C}$ to $1500{ }^{\circ} \mathrm{C}$.

As shown in Figure 4, the maximum sintering stress in the YSZ oxide pellets containing a lumped $\mathrm{Gd}_{2} \mathrm{O}_{3}$ mini-pellet was almost constant in the temperature range $25-1100{ }^{\circ} \mathrm{C}$ and began increasing almost exponentially at approximately 1150 ${ }^{\circ} \mathrm{C}$, corresponding to the temperature at which the YSZ pellet started to shrink (see Figure 2). As the pre-sintering temperature increased from $1400{ }^{\circ} \mathrm{C}$ to $1600{ }^{\circ} \mathrm{C}$, the maximum sintering stress increased, which could be attributed to the increase in the shrinkage rate mismatch (see Figure 2). Previous experimental observations (Mistarihi et al., 2018) showed no interfacial cracks

TABLE 1 | Dimensions of $\mathrm{Gd}_{2} \mathrm{O}_{3}$ mini-pellets after pre-sintering at different temperatures.

\begin{tabular}{lccc}
\hline & \multicolumn{3}{c}{ Initial sintering temperature $\left({ }^{\circ} \mathbf{C}\right)$} \\
\cline { 2 - 4 } & $\mathbf{1 4 0 0}$ & $\mathbf{1 5 0 0}$ & $\mathbf{1 6 0 0}$ \\
\hline Height $(\mathrm{mm})$ & $1.67 \pm 0.01$ & $1.6 \pm 0.05$ & $1.54 \pm 0.01$ \\
Diameter $(\mathrm{mm})$ & $2.76 \pm 0.03$ & $2.66 \pm 0.04$ & $2.57 \pm 0.03$
\end{tabular}

in YSZ pellets containing lumped $\mathrm{Gd}_{2} \mathrm{O}_{3}$ mini-pellets presintered at $1400{ }^{\circ} \mathrm{C}$, while cracks appeared in the YSZ oxide pellets containing lumped $\mathrm{Gd}_{2} \mathrm{O}_{3}$ mini-pellets pre-sintered at $1500{ }^{\circ} \mathrm{C}$ or higher. The maximum sintering stress in the YSZ oxide pellet containing a lumped $\mathrm{Gd}_{2} \mathrm{O}_{3}$ mini-pellet pre-sintered at $1400{ }^{\circ} \mathrm{C}$ during the fabrication process was calculated by FEA as approximately $120 \mathrm{MPa}$; that with the mini-pellets presintered at $1500{ }^{\circ} \mathrm{C}$ was approximately $150 \mathrm{MPa}$. This indicates that sintering stresses in the range 120-150 MPa would result in the formation of interfacial cracks in the YSZ oxide pellet containing lumped $\mathrm{Gd}_{2} \mathrm{O}_{3}$. The flexural strength of the fully dense YSZ at room temperature is approximately $1000 \mathrm{MPa}$ (Masaki, 1986) and it decreases almost linearly with increasing porosity to $170 \mathrm{MPa}$ for YSZ with an RD of $40 \%$ (Gain et al., 2006). However, simulation studies of the residual stresses during the fabrication of ceramic composites have shown that residual stresses as low as $25 \mathrm{kPa}$ (Schoenberg et al., 2006) or $90 \mathrm{MPa}$ (DeHoff et al., 2008) can cause the formation of interfacial cracks in ceramic composites.

Figure 5 shows the stress distribution in the YSZ oxide pellet containing either a lumped $\mathrm{Gd}_{2} \mathrm{O}_{3}$ sphere $(r=0.75 \mathrm{~mm})$ or minipellet $(r=h=0.83 \mathrm{~mm}$ ) with the same volume of approximately $1.77 \mathrm{~mm}^{3}$ and the shrinkage rate of the $1400{ }^{\circ} \mathrm{C}$ pre-sintered $\mathrm{Gd}_{2} \mathrm{O}_{3}$ at a sintering temperature of $1300^{\circ} \mathrm{C}$.

As shown in Figure 5, the addition of $\mathrm{Gd}_{2} \mathrm{O}_{3}$ spheres resulted in the formation of symmetric stresses around the interface. Meanwhile, the $\mathrm{Gd}_{2} \mathrm{O}_{3}$ mini-pellet caused the formation of localized stresses at the edges of the mini-pellet. The formation of these localized stresses indicates that cracks would form in these areas, which is in good agreement with the experimental observation presented in our previous study (Mistarihi et al., 2018), where interfacial cracks in YSZ pellets containing lumped $\mathrm{Gd}_{2} \mathrm{O}_{3}$ mini-pellets were observed at the mini-pellet edges. 


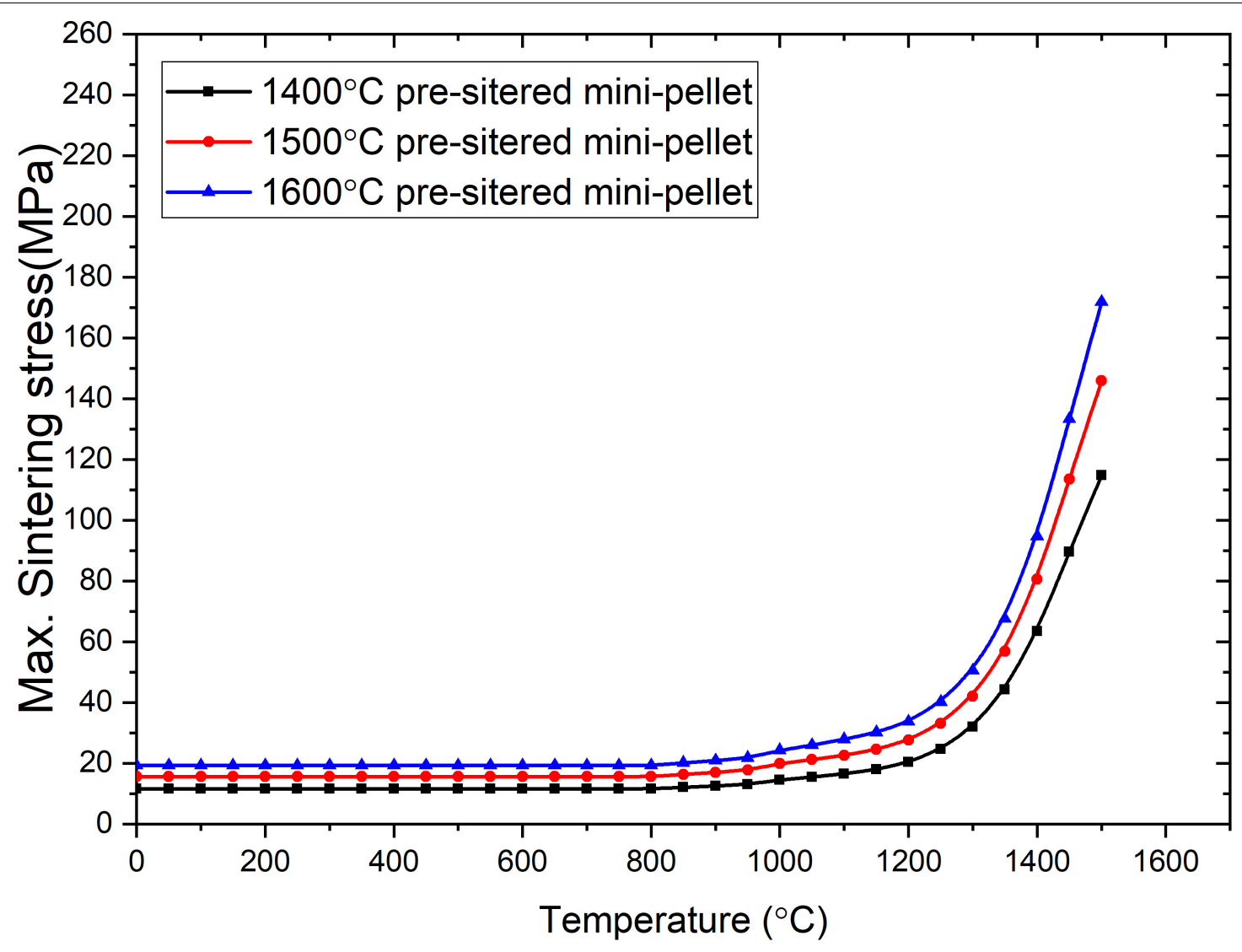

FIGURE 4 | FEA-predicted maximum sintering stresses in $\mathrm{YSZ}$ oxide pellet containing a lumped $\mathrm{Gd}_{2} \mathrm{O}_{3}$ mini-pellet pre-sintered at $1400{ }^{\circ} \mathrm{C}$, $1500{ }^{\circ} \mathrm{C}$, or $1600{ }^{\circ} \mathrm{C}$.

The FEA-calculated maximum sintering stresses in YSZ oxide pellets containing either a lumped $\mathrm{Gd}_{2} \mathrm{O}_{3}$ sphere $(r=0.75 \mathrm{~mm})$ or mini-pellet ( $r=h=0.83 \mathrm{~mm}$ ) with equal volume and shrinkage rates during the sintering process are shown in Figure 6. In order to investigate the effect of the dimensions of the $\mathrm{Gd}_{2} \mathrm{O}_{3}$ mini-pellets on the sintering stresses developed during the manufacturing of YSZ oxide pellets containing lumped $\mathrm{Gd}_{2} \mathrm{O}_{3}$ mini-pellets, simulation models were also developed with $\mathrm{Gd}_{2} \mathrm{O}_{3}$ mini-pellets of equal volume to the spheres but the reduced $r / h$ ratio of 0.5 . The maximum sintering stresses developed during the manufacturing of the YSZ oxide pellet containing a lumped $\mathrm{Gd}_{2} \mathrm{O}_{3}$ mini-pellet $(r=1 / 2 h=0.65 \mathrm{~mm})$ as calculated by FEA are also shown in Figure 6.

The addition of mini-pellets yielded higher sintering stress over the entire temperature range, which can be attributed to the localized stresses at the edges of the mini-pellets. These higher localized sintering stresses are mainly caused by the outward bending of the $\mathrm{Gd}_{2} \mathrm{O}_{3}$ mini-pellet due to the shrinkage of the YSZ. The temperature gradient caused uniform shrinkage of the $\mathrm{Gd}_{2} \mathrm{O}_{3}$ spheres, yielding lower and symmetric sintering stresses in the YSZ oxide pellet containing a lumped $\mathrm{Gd}_{2} \mathrm{O}_{3}$ sphere. DeHoff et al. (2008) studied the stress distributions of bilayer open-ended cylindrical ceramics and spherical-core ceramics and found that the open-ended cylinder ceramics showed localized stresses at the upper edges of the cylinders, whereas the spherical-core ceramics had symmetric stress distributions around the core-shell interface. This indicates that the use of spherical $\mathrm{Gd}_{2} \mathrm{O}_{3}$ is better than that of mini-pellets to maintain the integrity of the CSBA fuel during fabrication. The localized stresses developed in the YSZ pellet containing a lumped $\mathrm{Gd}_{2} \mathrm{O}_{3}$ mini-pellet can be reduced by decreasing the aspect ratio of the mini-pellet because this diminishes the outward bending caused by the temperature gradient.

Figure 7 shows the FEA-calculated maximum sintering stress in YSZ oxide pellets containing lumped $\mathrm{Gd}_{2} \mathrm{O}_{3}$ spheres of equal size $(r=0.75 \mathrm{~mm})$ but the shrinkage rates of $\mathrm{Gd}_{2} \mathrm{O}_{3}$ sintered at $1400{ }^{\circ} \mathrm{C}, 1500{ }^{\circ} \mathrm{C}$, and $1600{ }^{\circ} \mathrm{C}$. As shown in Figure 7, the maximum sintering stress during fabrication was increased with increases in the pre-sintering temperature of the lumped $\mathrm{Gd}_{2} \mathrm{O}_{3}$, which could be attributed to the increases in the shrinkage rate mismatch.

According to the experimental observation in our previous study (Mistarihi et al., 2018), interfacial cracks were observed in YSZ oxide pellets containing lumped $\mathrm{Gd}_{2} \mathrm{O}_{3}$ mini-pellets presintered at $1500{ }^{\circ} \mathrm{C}$ or higher, but not in YSZ containing lumped $\mathrm{Gd}_{2} \mathrm{O}_{3}$ spherical particles pre-sintered at $1600{ }^{\circ} \mathrm{C}$. As can be seen from Figure 7, the calculated maximum sintering stress in the YSZ pellet containing a $0.75-\mathrm{mm}$-radius lumped $\mathrm{Gd}_{2} \mathrm{O}_{3}$ sphere pre-sintered at $1600{ }^{\circ} \mathrm{C}$ is approximately $105 \mathrm{MPa}$. The maximum calculated sintering stress in the YSZ pellet containing 


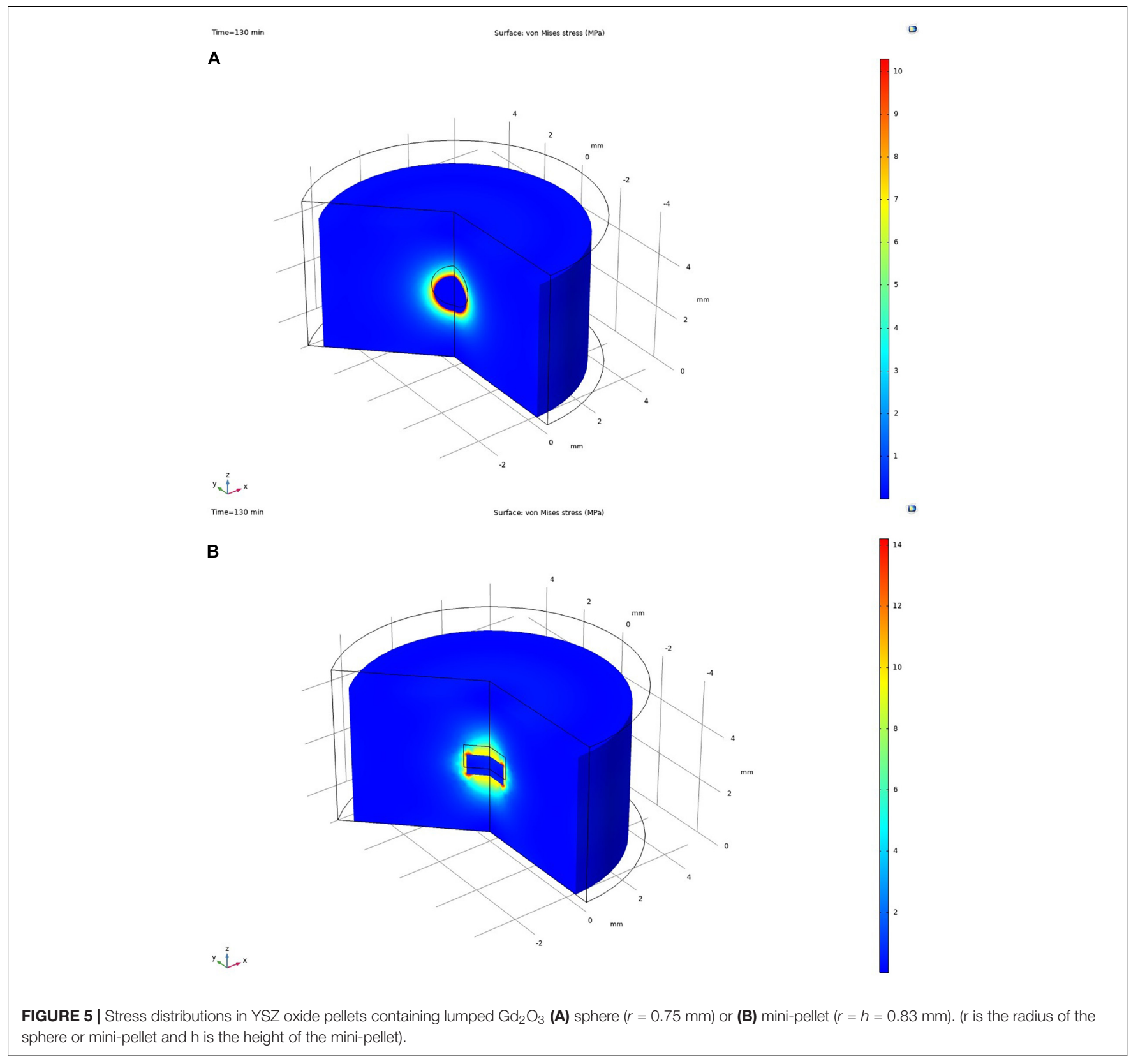

the $1500{ }^{\circ} \mathrm{C}$ pre-sintered mini-pellet was approximately $150 \mathrm{MPa}$ (Figure 4). Therefore, the absence of interfacial cracks in the case of the YSZ pellet containing $\mathrm{Gd}_{2} \mathrm{O}_{3}$ spherical particles presintered at $1600{ }^{\circ} \mathrm{C}$ could be attributed to the reduced symmetric sintering stress relating to their smaller sizes and spherical shapes, compared to those of the $1500{ }^{\circ} \mathrm{C}$ pre-sintered minipellet.

The effect of the $\mathrm{Gd}_{2} \mathrm{O}_{3}$ sphere size on the maximum sintering stress in YSZ oxide pellets containing lumped $\mathrm{Gd}_{2} \mathrm{O}_{3}$ spheres with the shrinkage rate of the $1400{ }^{\circ} \mathrm{C}$ sintered $\mathrm{Gd}_{2} \mathrm{O}_{3}$ during sintering is shown in Figure 8. As shown, the maximum sintering stress was increased with increases in the size of the $\mathrm{Gd}_{2} \mathrm{O}_{3}$ spheres. However, the increase was much smaller than that observed with increases in the $\mathrm{Gd}_{2} \mathrm{O}_{3}$ shrinkage rates. This indicates that the sintering stresses developed in the YSZ oxide pellets containing lumped $\mathrm{Gd}_{2} \mathrm{O}_{3}$ spheres are mostly controlled by the $\mathrm{Gd}_{2} \mathrm{O}_{3}$ shrinkage rate.

\section{$\mathrm{UO}_{2}$ Fuel Pellet}

Experimental studies using $\mathrm{UO}_{2}$ are expensive and present high levels of radiotoxicity. In an experimental demonstration (Mistarihi et al., 2018) of the fabrication of oxide pellets containing lumped $\mathrm{Gd}_{2} \mathrm{O}_{3}$ spherical particles, mini-pellets, or rods, YSZ was used as a surrogate for $\mathrm{UO}_{2}$ because it has a similar crystal structure, high melting temperature, and sintering kinetics. However, for fabrication studies, the shrinkage rate and 


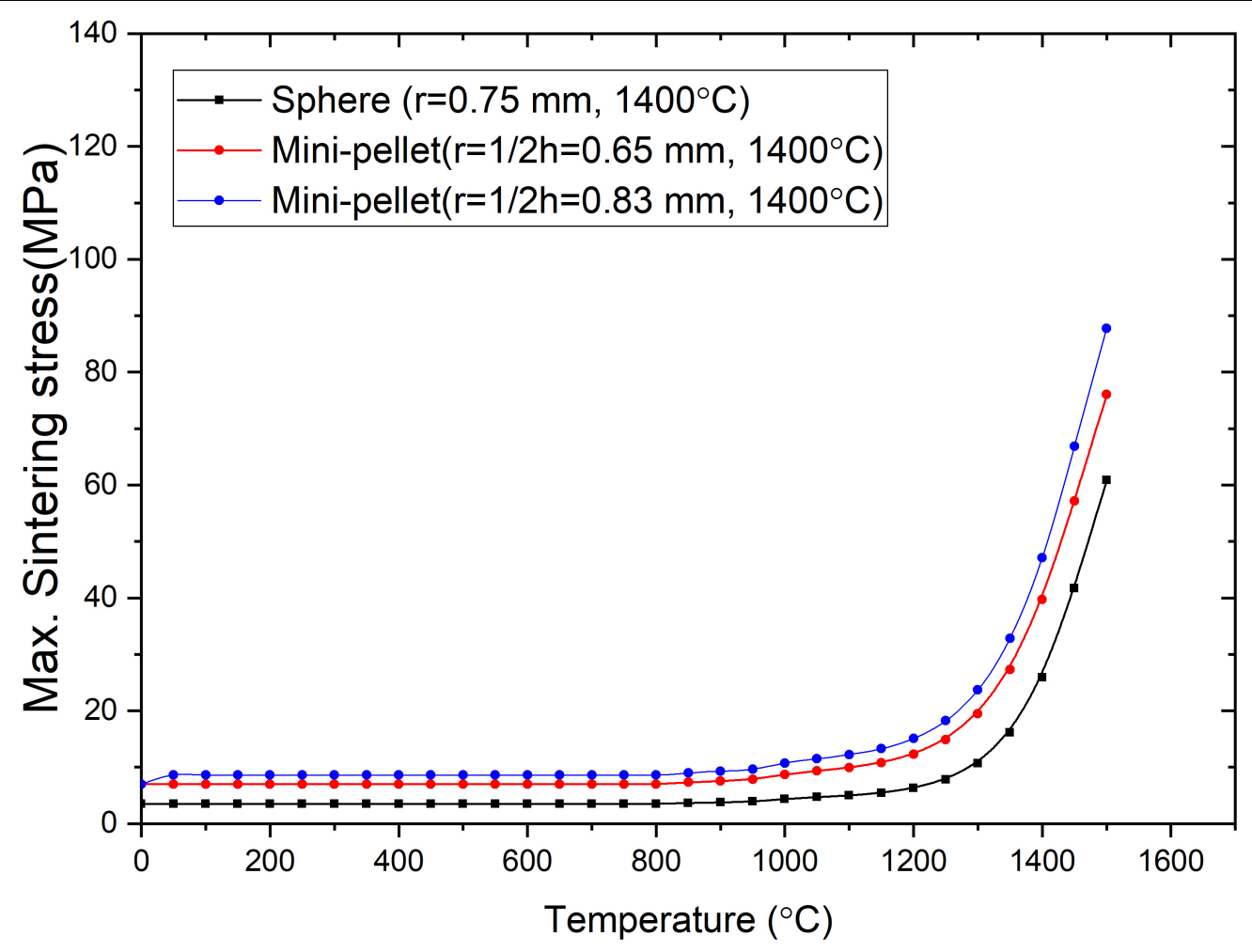

FIGURE 6 | FEA-calculated maximum sintering stress in YSZ oxide pellets containing lumped $\mathrm{Gd}_{2} \mathrm{O}_{3}$ spheres and mini-pellets of the same volume and shrinkage rate.

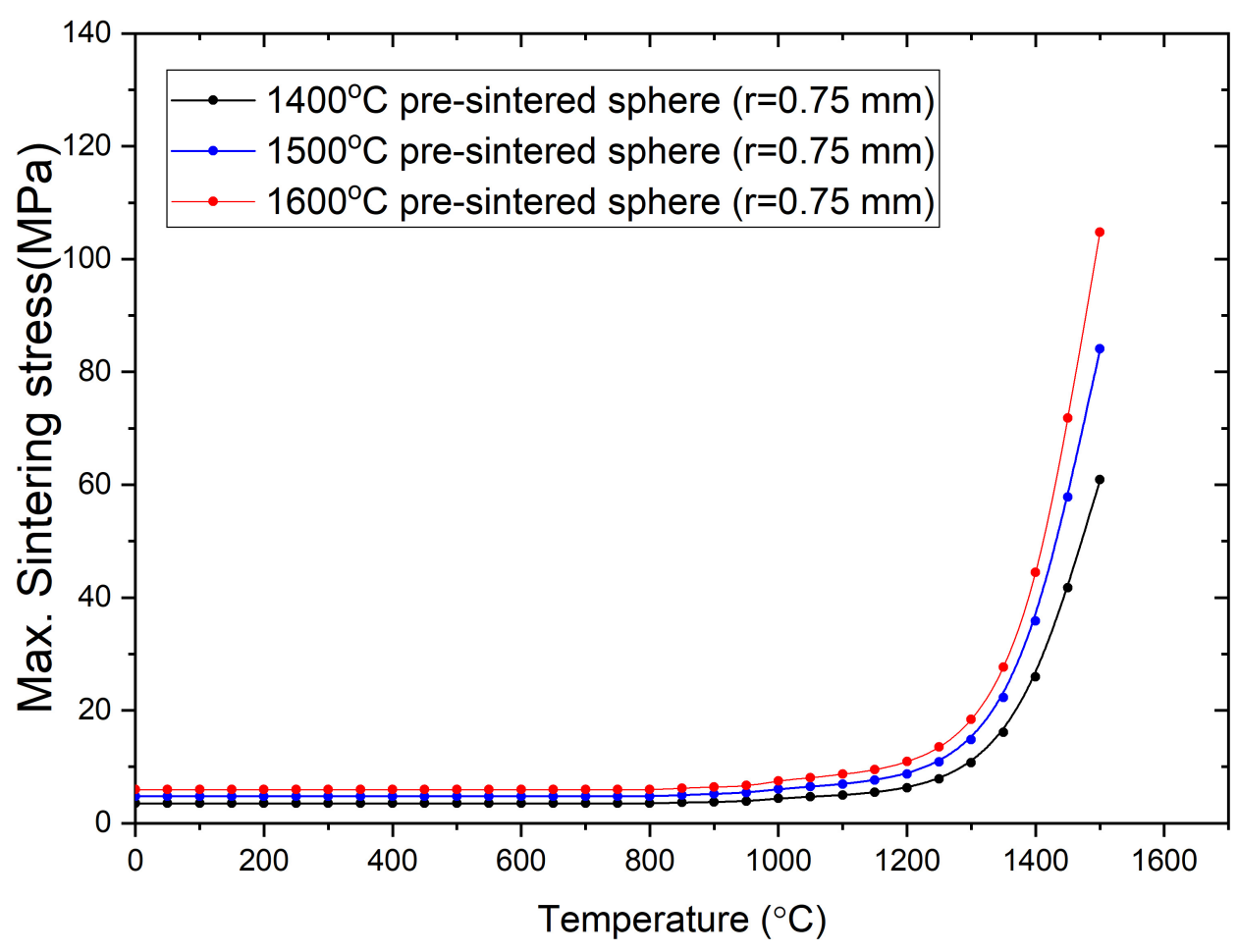

FIGURE 7 | FEA-calculated maximum sintering stress in YSZ oxide pellets containing lumped $\mathrm{Gd}_{2} \mathrm{O}_{3}$ spheres of equal size $(r=0.75 \mathrm{~mm})$ but different shrinkage rates. 


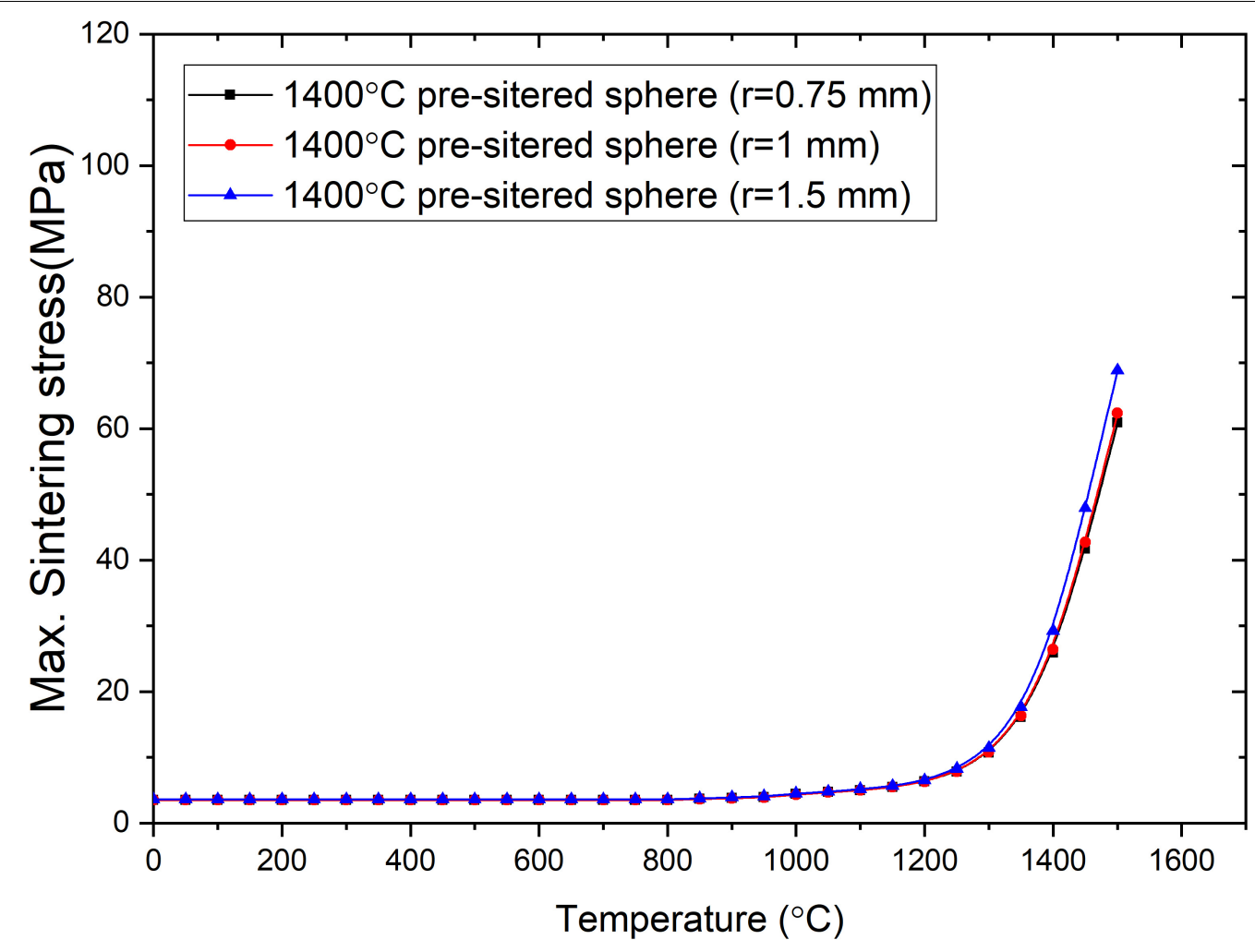

FIGURE 8 | FEA-calculated maximum sintering stress in YSZ oxide pellets containing lumped $\mathrm{Gd}_{2} \mathrm{O}_{3}$ spheres of different sizes but equal shrinkage rates.

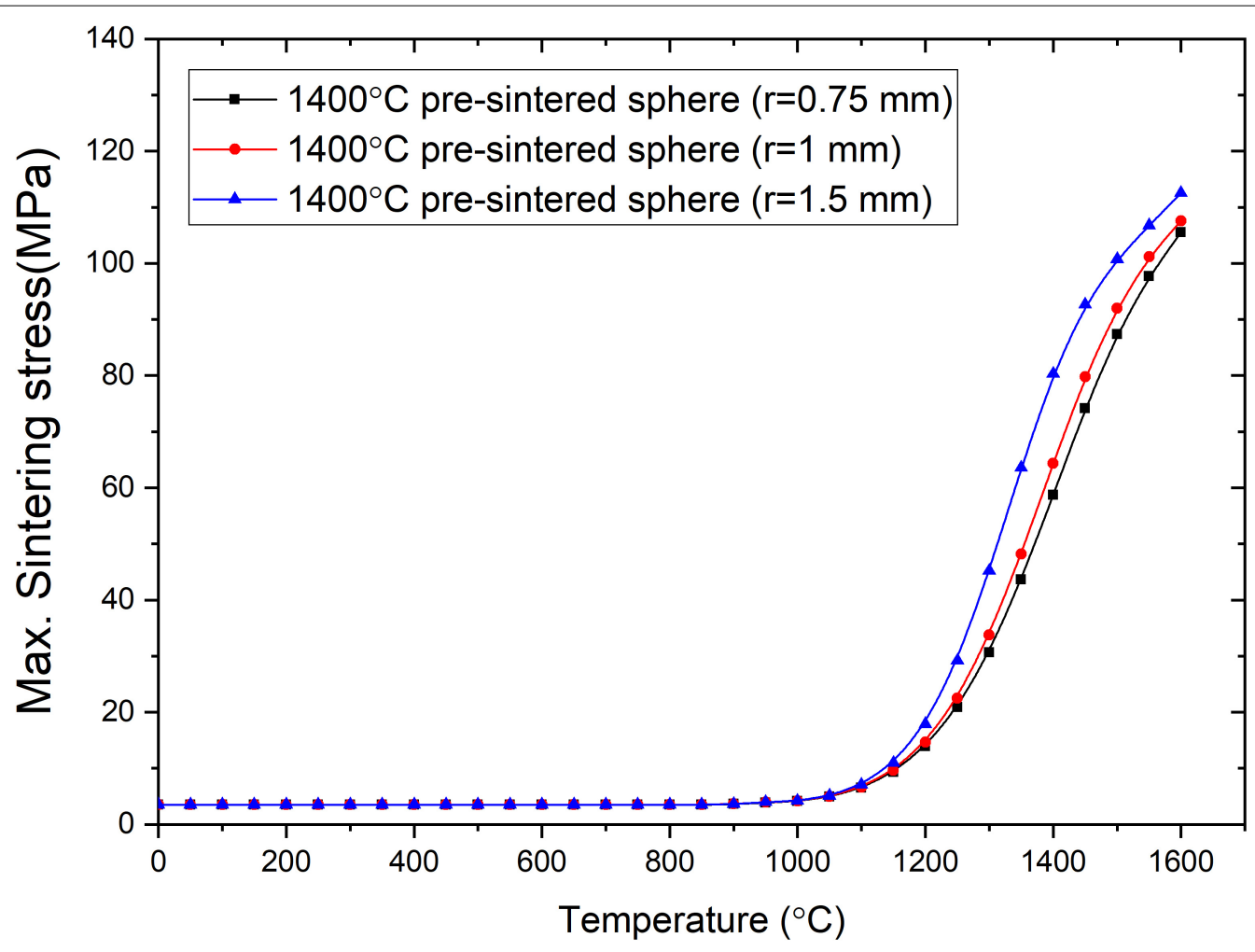

FIGURE 9 | FEA-calculated maximum sintering stress in $\mathrm{UO}_{2}$ pellets containing lumped $\mathrm{Gd}_{2} \mathrm{O}_{3}$ spheres of different sizes but equal shrinkage rates. 


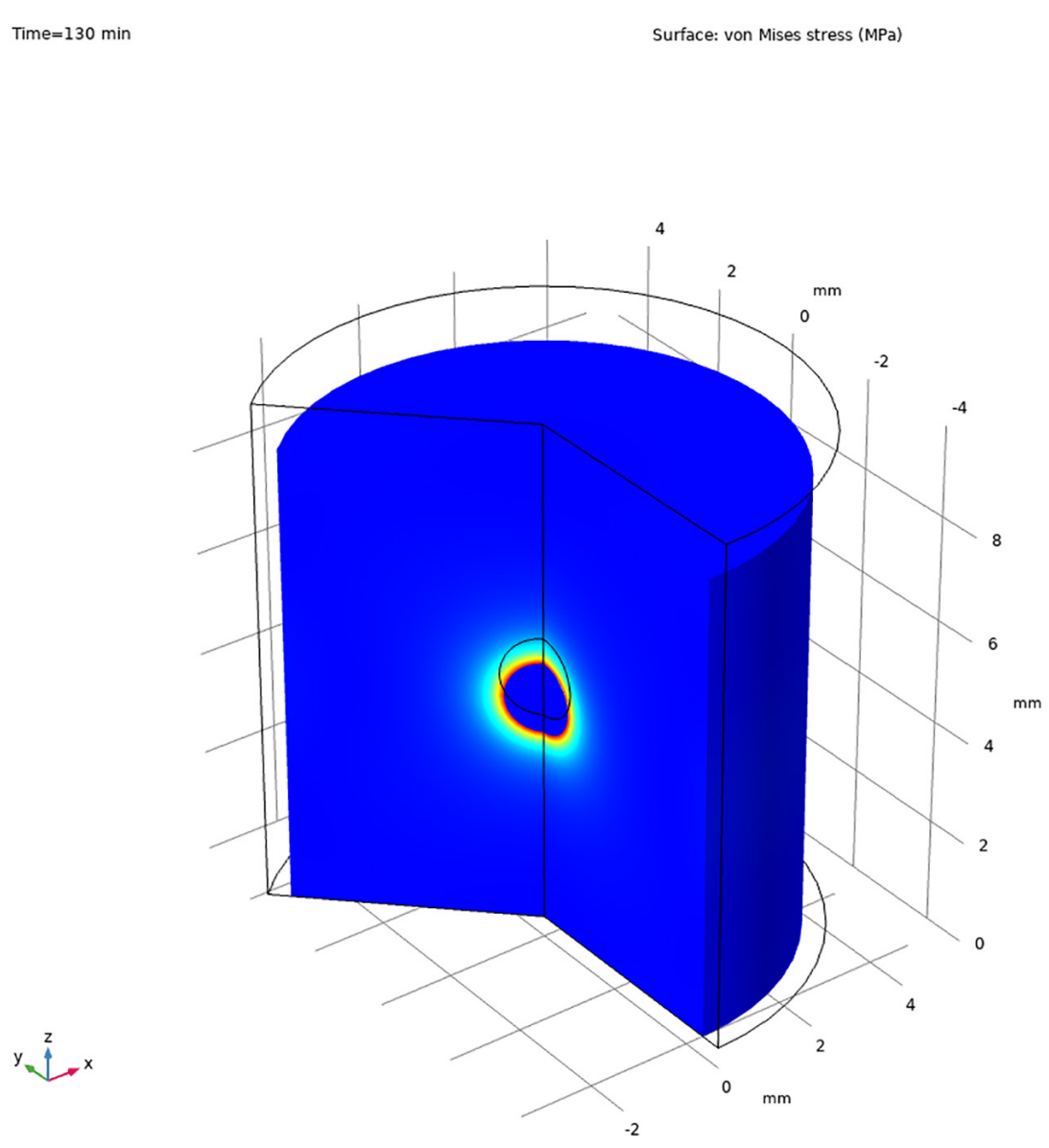

FIGURE 10 | Stress distribution in $\mathrm{UO}_{2}$ pellet containing a lumped $\mathrm{Gd}_{2} \mathrm{O}_{3}$ sphere $(r=0.75 \mathrm{~mm})$.

TEC of YSZ and $\mathrm{UO}_{2}$ must be similar, as well as the diffusivity of $\mathrm{Gd}^{3+}$ in the $\mathrm{YSZ}$ and $\mathrm{UO}_{2}$ matrices.

Figure 9 shows the FEA-calculated maximum sintering stress in $\mathrm{UO}_{2}$ pellets containing a lumped $\mathrm{Gd}_{2} \mathrm{O}_{3}$ sphere with a shrinkage rate of $1400{ }^{\circ} \mathrm{C}$ pre-sintered $\mathrm{Gd}_{2} \mathrm{O}_{3}$ but different sizes $(r=0.75,1,1.5 \mathrm{~mm})$. As shown in Figure 9, the maximum sintering stress during the fabrication process was increased with increases in the size of the lumped $\mathrm{Gd}_{2} \mathrm{O}_{3}$. However, the calculated maximum sintering stresses in the $\mathrm{UO}_{2}$ fuel pellets were higher than those reported for YSZ pellets. The maximum sintering stresses in $\mathrm{UO}_{2}$ containing lumped $\mathrm{Gd}_{2} \mathrm{O}_{3}$ sphere with a radius of $1.5 \mathrm{~mm}$ at $1300{ }^{\circ} \mathrm{C}, 1400{ }^{\circ} \mathrm{C}$, and $1500{ }^{\circ} \mathrm{C}$ were about 45.2, 80.3, and $101 \mathrm{MPa}$, respectively, whereas the maximum sintering stresses determined in YSZ pellet containing the same $\mathrm{Gd}_{2} \mathrm{O}_{3}$ sphere and at the same sintering temperatures were about 11.4, 29.2, and 68.8 MPa, respectively (see Figure 8). This could be attributed to the greater mismatch in the shrinkage rates of $\mathrm{UO}_{2}$ and $\mathrm{Gd}_{2} \mathrm{O}_{3}$ relative to that of $\mathrm{YSZ}$ and $\mathrm{Gd}_{2} \mathrm{O}_{3}$ (see Figure 2).

The stress distribution in the $\mathrm{UO}_{2}$ pellet containing a lumped $\mathrm{Gd}_{2} \mathrm{O}_{3}$ sphere $(r=0.75 \mathrm{~mm})$ with the shrinkage rate of 1400 ${ }^{\circ} \mathrm{C}$ pre-sintered $\mathrm{Gd}_{2} \mathrm{O}_{3}$ at the sintering temperature of $1300{ }^{\circ} \mathrm{C}$ is shown in Figure 10. The stress distribution was symmetric, similar to that in the YSZ pellet with the same conditions; however, the stress values were higher than those reported in
YSZ, which can again be attributed to the higher shrinkage rate mismatch between $\mathrm{UO}_{2}$ and $\mathrm{Gd}_{2} \mathrm{O}_{3}$ relative to that between YSZ and $\mathrm{Gd}_{2} \mathrm{O}_{3}$ (see Figure 2).

Owing to the absence of sufficient experimental data for CSBA fuel using $\mathrm{UO}_{2}$, it is difficult to set threshold stress values for the formation of interfacial cracks in $\mathrm{UO}_{2}$-based CSBA. However, the fabrication of $\mathrm{UO}_{2}$ oxide pellets containing lumped $\mathrm{Gd}_{2} \mathrm{O}_{3}$ spherical particles pre-sintered at $1400{ }^{\circ} \mathrm{C}$ was reported by $\mathrm{Oh}$ et al. (2017) using the conventional fabrication conditions for $\mathrm{UO}_{2}$ of pressing under 3 ton $/ \mathrm{cm}^{2}$ followed by sintering at $1700^{\circ} \mathrm{C}$ for $4 \mathrm{~h}$ in an $\mathrm{H}_{2}$ atmosphere at approximately $5{ }^{\circ} \mathrm{C} / \mathrm{min}$. Similar results were observed regarding the absence of interfacial cracks and the formation of the gadolinium urinate phase at the interface between $\mathrm{UO}_{2}$ and $\mathrm{Gd}_{2} \mathrm{O}_{3}$.

\section{CONCLUSION}

The sintering stresses developed in the YSZ oxide pellets containing either lumped $\mathrm{Gd}_{2} \mathrm{O}_{3}$ spheres or mini-pellets during fabrication from $25{ }^{\circ} \mathrm{C}$ to $1500{ }^{\circ} \mathrm{C}$ were simulated using the FEA method. Thermal and linear elastic models were used to simulate the sintering stresses in lumped $\mathrm{Gd}_{2} \mathrm{O}_{3}$, while thermal and sintering models based on the continuum theory of sintering 
were used to simulate those in the YSZ powder compact. These models were coupled and implemented using COMSOL Multiphysics code.

The critical sintering stresses for the formation of interfacial cracks in YSZ oxide pellets containing lumped $\mathrm{Gd}_{2} \mathrm{O}_{3}$ were determined by comparing the FEA-calculated stresses in YSZ oxide pellets containing lumped $\mathrm{Gd}_{2} \mathrm{O}_{3}$ mini-pellets with the shrinkage rates of $1400^{\circ} \mathrm{C}, 1500{ }^{\circ} \mathrm{C}$, and $1600{ }^{\circ} \mathrm{C}$ sintered $\mathrm{Gd}_{2} \mathrm{O}_{3}$ with experimental observations. It was found that sintering stresses in the range of 120-150 MPa could cause the formation of interfacial cracks in these pellets.

The effects of the shape, shrinkage rate, and size of lumped $\mathrm{Gd}_{2} \mathrm{O}_{3}$ on the formation of cracks during fabrication were studied. It was found that the addition of cylindrical $\mathrm{Gd}_{2} \mathrm{O}_{3}$ mini-pellets resulted in localized and higher stresses at the mini-pellet edges. In contrast, the addition of $\mathrm{Gd}_{2} \mathrm{O}_{3}$ spherical particles yielded symmetric and lower stresses at the interface between the $\mathrm{Gd}_{2} \mathrm{O}_{3}$ and YSZ. Increases in the shrinkage rate and size of $\mathrm{Gd}_{2} \mathrm{O}_{3}$ resulted in higher sintering stresses in the YSZ oxide pellets containing lumped $\mathrm{Gd}_{2} \mathrm{O}_{3}$.

The sintering stresses developed during the fabrication of $\mathrm{UO}_{2}$ containing lumped $\mathrm{Gd}_{2} \mathrm{O}_{3}$ spheres were also estimated. Similar behaviors to those of YSZ were observed. However, the magnitude of the sintering stress was higher because of the higher

\section{REFERENCES}

Agarwal, B. D. (1972). Micromechanics Analysis of Composite Materials Using Finite Element Methods. Ph.D. thesis, Illinois Institute of Technology, Chicago.

Choe, J., Shin, H. C., and Lee, D. (2016a). New burnable absorber for long-cycle low boron operation of PWRs. Ann. Nucl. Energy 88, 272-279. doi: 10.1016/j. anucene.2015.11.011

Choe, J., Zheng, Y., Lee, D., and Shin, H. C. (2016b). Boron-free small modular pressurized water reactor design with new burnable absorber. Int. J. Energy Res. 40, 2128-2135. doi: $10.1002 / \mathrm{er}$

Davidge, R. W., and Green, T. J. (1968). The strength of two-phase ceramic glass materials. J. Mater. Sci. 3, 629-634. doi: 10.1007/BF00757910

DeHoff, P. H., Barrett, A. A., Lee, R. B., and Anusavice, K. J. (2008). Thermal compatibility of dental ceramic systems using cylindrical and spherical geometries. Dent. Mater. 24, 744-752. doi: 10.1016/j.dental.2007. 08.008

Delale, F. (1988). Critical fiber size for microcrack suppression in ceramic-fiber ceramic-matrix compoistes. Eng. Fract. Mech. 31, 145-155.

Dole, S. L., and Hunter, O. (1976). Elastic properties of some $\mathrm{Gd}_{2} \mathrm{O}_{3}-\mathrm{HfO}_{2}$ compositions. J. Nucl. Mater. 59, 207-214.

Durazzo, M., Saliba-Silva, A. M., Urano De Carvalho, E. F., and Riella, H. G. (2013). Sintering behavior of $\mathrm{UO}_{2}-\mathrm{Gd}_{2} \mathrm{O}_{3}$ fuel: pore formation mechanism. J. Nucl. Mater. 433, 334-340. doi: 10.1016/j.jnucmat.2012.09.033

Fink, J. (2000). Thermophysical properties of uranium dioxide. J. Nucl. Mater. 279, 1-18. doi: 10.1016/S0022-3115(99)00273-1

Fleming, R. F. (1982). Neutron self-shielding factors for simple geometrics. Int. J. Appl. Radiat. Isot. 33, 1263-1268. doi: 10.1016/0020-708X(82)90 247-2

Gain, A. K., Song, H. Y., and Lee, B. T. (2006). Microstructure and mechanical properties of porous yttria stabilized zirconia ceramic using poly methyl methacrylate powder. Scr. Mater. 54, 2081-2085. doi: 10.1016/j.scriptamat. 2006.03.009

Galperin, A., Segev, M., and Radkowsky, A. (1986). Substitution of the Soluble boron reactivity control system of a pressurized water reactor by gadolium burnable poisons. Nucl. Technol. 75, 127-133. doi: 10.13182/NT86-A33855 shrinkage rate mismatch between $\mathrm{UO}_{2}$ and $\mathrm{Gd}_{2} \mathrm{O}_{3}$ relative to that between $\mathrm{YSZ}$ and $\mathrm{Gd}_{2} \mathrm{O}_{3}$.

\section{DATA AVAILABILITY STATEMENT}

The original contributions presented in the study are included in the article/supplementary material, further inquiries can be directed to the corresponding author.

\section{AUTHOR CONTRIBUTIONS}

QM did the finite element simulation and wrote the article. HR supervised and reviewed the written article. Both authors contributed to the article and approved the submitted version.

\section{FUNDING}

This study was supported by the KAI-NEET Institute of KAIST and the National Research Foundation (NRF) of Korea grant funded by the Korean Government (Ministry of Science, ICT and Future Planning) (NRF-2016R1A5A1013919, NRF2018M2A8A1083889, and NRF-2019M2D1A1067210).

Grossbeck, M. L., Renier, J.-P. A., and Grossbeck, M. L. (2001). Development of improved Burnable Poisons for Commercial Nuclear Power Reactors. Oak Ridge, TN: Oak Ridge National Laboratory.

Haglund, J. A., and Hunter, O. (1973). Elastic properties of polycrystalline monoclinic $\mathrm{Gd}_{2} \mathrm{O}_{3}$. J. Am. Ceram. Soc. 56, 327-330. doi: 10.1111/j.1151-2916. 1973.tb12506.x

Hall, R. O. A., and Mortimer, M. J. (1986). A critical review of the surface energy of $\mathrm{UO}_{2}$. J. Less Common Met. 121, 341-345. doi: 10.1097/00152193-19830600000031

IAEA (1995). Characteristics and Use of Urania-Gadolinia Fuels. Vienna: IAEA.

Kerrisk, J. F., and Clifton, D. G. (1972). Smoothed values of the enthalpy and heat capacity of $\mathrm{UO}_{2}$. Nucl. Tech. 16, 531-535. doi: 10.13182/NT72-6

Li, C., Wu, Y., Wang, Y., Wang, K., Wang, M., Tian, W., et al. (2020). Analysis on the behavior of dispersed plate-type fuel based on fluid-solid coupling method. Prog. Nucl. Energy 126:103398. doi: 10.1016/j.pnucene.2020.103398

Lucuta, P. G., Matzke, H., and Hastings, I. J. (1996). A pragmatic approach to modelling thermal conductivity of irradiated $\mathrm{UO}_{2}$ fuel: review and recommendations. J. Nucl. Mater. 232, 166-180. doi: 10.1016/S0022-3115(96) 00404-7

Manière, C., Zahrah, T., and Olevsky, E. A. (2017). Fully coupled electromagneticthermal-mechanical comparative simulation of direct vs hybrid microwave sintering of $3 \mathrm{Y}-\mathrm{ZrO}_{2}$. J. Am. Ceram. Soc. 100, 2439-2450. doi: 10.1111/jace. 14762

Masaki, T. (1986). Mechanical properties of toughened $\mathrm{ZrO}_{2}-\mathrm{Y}_{2} \mathrm{O}_{3}$ ceramics J. Am. Ceram. Soc. 69, 638-640. doi: 10.1111/j.1151-2916.1986.tb04823.x

Mistarihi, Q. M., Park, W., Nam, K., Yahya, M.-S., Kim, Y., and Ryu, H. J. (2018). Fabrication of oxide pellets containing lumped $\mathrm{Gd}_{2} \mathrm{O}_{3}$ using $\mathrm{Y}_{2} \mathrm{O}_{3}$-stabilized $\mathrm{ZrO}_{2}$ for burnable absorber fuel applications. Int. J. Energy Res 42, 2141-2151. doi10.1002/er.3995

Nguyen, X. H., Kim, C. H., and Kim, Y. (2019). An advanced core design for a soluble-boron-free small modular reactor ATOM with centrally-shielded burnable absorber. Nucl. Eng. Technol. 51, 369-376. doi: 10.1016/j.net.2018. 10.016

Oh, J. S., Mistarihi, Q., Ryu, H. J., and Kim, D.-J. (2017). "Fabrication of Gadolinia-containing $\mathrm{UO}_{2}$ fuel pellet," in Proceedings of the 42nd International 
Conference and Expo on Advanced Ceramics and Composites, Daytona Beach, FL.

Olevsky, E. A. (1998). Theory of sintering: from discrete to continuum. Mater. Sci. Eng. R Rep. 23, 41-100. doi: 10.1016/S0927-796X(98)00009-6

Olevsky, E. A., Garcia-Cardona, C., Bradbury, W. L., Haines, C. D., Martin, D. G., and Kapoor, D. (2012). Fundamental aspects of spark plasma sintering: II. Finite element analysis of scalability. J. Am. Ceram. Soc. 95, 2414-2422. doi: 10.1111/j. $\backslash$ hbox $\{1551-2916\} .2012 .05096 . x$

Riedel, H., Meyer, D., Svoboda, J., and Zipse, H. (1993). Numerical simulation of die pressing and sintering - development of constitutive equations. Int. J. Refract. Met. Hard Mater. 12, 55-60. doi: 10.1016/0263-4368(93)90016-9

Schoenberg, S. E., Green, D. J., Segall, A. E., Messing, G. L., Grader, A. S., and Halleck, P. M. (2006). Stresses and distortion due to green density gradients during densification. J. Am. Ceram. Soc. 89, 3027-3033. doi: 10.1111/j.15512916.2006.01182.x

Selsing, J. (1961). Internal stresses in ceramics. J. Am. Ceram. Soc. 44, 419-419. doi: 10.1111/j.1151-2916.1961.tb15475.x

Sglavo, V. M., and Bellettati, N. (2017). Ceramic laminates with improved mechanical reliability by tailoring the porosity of the constituting layers. J. Eur. Ceram. Soc. 37, 1643-1650. doi: 10.1016/j.jeurceramsoc.2016. 11.022

Siefken, L. J., Coryell, E. W., Harvego, E. A., and Hohorst, J. K. (2001). MATPRO-A Library of Materials Properties for Light-Water-Reactor Accident Analysi. Idaho Falls, ID: Idaho National Engineering and Environmental Laboratory.

Song, X., Lu, J., Zhang, T., and Ma, J. (2011). Two-stage master sintering curve approach to sintering kinetics of undoped and $\mathrm{Al}_{2} \mathrm{O}_{3}$-doped $8 \mathrm{Mol} \%$ yttria-stabilized cubic zirconia. J. Am. Ceram. Soc. 94, 1053-1059. doi: 10.1111/ j.1551-2916.2010.04199.x

Tsoga, A., and Nikolopoulos, P. (1996). Surface and grain-boundary energies in yttria-stabilized zirconia (YSZ-8 mol\%). J. Mater. Sci. 31, 5409-5413. doi: 10. 1007/BF01159310

Yahya, M.-S., and Kim, Y. (2017a). An innovative core design for a soluble-boronfree small pressurized water reactor. Int. J. Energy Res. 41, 1-9. doi: 10.1002/er. 3792

Yahya, M.-S., and Kim, Y. (2017b). "Centrally-shielded burnable absorber for LWR fuel," in Proceedings of the International Congress on Advances in Nuclear Power Plants (Fukui and Kyoto: American nuclear society).

Yeo, S., McKenna, E., Baney, R., Subhash, G., and Tulenko, J. (2013). Enhanced thermal conductivity of uranium dioxide-silicon carbide composite fuel pellets prepared by Spark Plasma Sintering (SPS). J. Nucl. Mater. 433, 66-73. doi: 10.1016/j.jnucmat.2012.09.015

Conflict of Interest: The authors declare that the research was conducted in the absence of any commercial or financial relationships that could be construed as a potential conflict of interest.

Copyright (c) 2021 Mistarihi and Ryu. This is an open-access article distributed under the terms of the Creative Commons Attribution License (CC BY). The use, distribution or reproduction in other forums is permitted, provided the original author(s) and the copyright owner(s) are credited and that the original publication in this journal is cited, in accordance with accepted academic practice. No use, distribution or reproduction is permitted which does not comply with these terms. 